\section{Prophylaxis of Dysrhythmias after Myocardial Infarction}

When a constant electrocardiographic monitoring system is applied to a patient in the first few hours after acute myocardial infarction, disturbances of rate, rhythm, or conduction have been recorded in as many as $95 \%$ of cases. Ventricular ectopic beats have been recorded in $75 \%$, major ventricular dysrhythmias in $50 \%$, and ventricular tachycardia or ventricular fibrillation in up to $37 \% .^{1-3}$ Because many transient repetitive disturbances will be missed if electrocardiographic recording is only intermittent, this high frequency of cardiac dysrhythmias after acute myocardial infarction has only recently been discovered.

Coronary care units save lives by the early detection and treatment of ventricular dysrhythmias. ${ }^{2}$ Since the incidence of dysrhythmias and of death fall pari passu with hours elapsing since the infarct, the coronary care units which receive their patients earliest see the greatest number of rhythm disturbances and stand to save the greatest number of lives. The physician now properly feels a sense of failure on seeing a "good heart" in the necropsy room, because myocardial infarction no longer need be fatal provided sufficient intact myocardium remains to support the circulation.

Unfortunately, ventricular dysrhythmias remain a:major cause of death even in coronary care units. Waiting for trouble means that the circulation to vital organs may have already been compromised by the time treatment begins. Moreover, catecholamine release may have already determined the continuation of the unstable electrical state of the heart, so that a dysrhythmia, once established, may be difficult or impossible to correct. Not least, the adverse effect of emergency therapy on the morale of the patient should be borne in mind.

Years ago first quinidine and then procainamide were tried for the prophylaxis of dysrhythmias after acute myocardial infarction, but with inconclusive results and some fatalities attributable to the therapy. ${ }^{4-6}$ More recently propranolol has been tried but found unsuitable because its depressant effect on the contractile force of the damaged heart more than outweighed its eurhythmic properties. ${ }^{7-9}$ A suitable drug should not only lower the incidence of rhythm disturbances but should do so without depressing the myocardial pump and without causing unpleasant side-effects. Preferably it should achieve a rapid and stable effect after being given by mouth

\footnotetext{
1 Julian, D. G., Valentine, P. A., and Miller, G. G., American fournal of Medicine, 1964, 37, 915.

2 Goble, A. J., Sloman, G., and Robinson, J. S., British Medical fournal, 1966, 1, 1005.

3 Lown, B., Fakhro, A. M., Hood, W. B., Jr., and Thorn, G. W. fournal of the American Medical Association, 1967, 199, 188. Cutts, F. B., and Rapoport, B., New England Fournal of Medicine, $1952,247,81$. Holmberg, S., and Bergman, H., Acta Medica Scandinavica, 1967, 181,
297.

6 Reynell, P. C., British Heart fournal, 1961, 23, 421.

7 Snow, P. J. D., Lancet, 1965, 2, 551

Balcon, R., Jewitt, D. E., Davies, J. P. H., and Oram, S., Lancet, 1966, 2, 917.

9 Clausen, J., et al., Lancet, 1966, 2, 920.

10 Koch-Weser, J., Klein, S. W., Foo-Canto, L. L., Castor, J. A., and DeSanctis, R. W., New England fournal of Medicine, 1969, 281,
}

and have a wide safety margin obviating the need for careful laboratory control.

In the coronary care unit of the Massachusetts General Hospital, Boston, procainamide given by mouth has been tested in a well-designed double-blind study. ${ }^{10}$ All the patients in the trial had suffered a recent myocardial infarct but were free from severe cardiac failure, shock, or atrioventricular dissociation. Patients received a loading dose of $1 \mathrm{~g}$. followed by $375 \mathrm{mg}$. every three hours, the dosage depending on body weight. Disturbances of rhythm were recognized as active and passive, the incidence of ventricular ectopic beats, tachycardia, and ventricular fibrillation being examined separately from atrial ectopic activity and from passive disturbances in atrioventricular conduction. Prophylactic therapy with procainamide decreased the percentage of patients suffering an active disturbance of rhythm of ventricular origin but there was no change in the incidence of disturbances of atrial rhythm or in the incidence of passive dysrhythmias. The effectiveness of the regimen was emphasized by the fact that 10 of the 33 patients in the placebo group were removed from it on account of active ventricular dysrhythmias which were unresponsive to lignocaine therapy but which were subsequently successfully treated with procainamide. Only one of the 37 procainamide-treated patients suffered similarly.

The safe and beneficial effect coincided with a plasma concentration of procainamide which lay between 4 and 6 mg. per litre. Unfortunately these close limits of plasma concentration were not always achieved on the dosage schedule chosen. The variations arose from individual differences in the absorption, the biological half-life, and in the distribution of the drug in the body. Ventricular tachydysrhythmias were observed only when the plasma concentration of procainamide lay below $4 \mathrm{mg}$./litre. Suspected adverse effects always coincided with plasma concentrations above $7 \mathrm{mg}$./litre but were observed in only three out of the seven patients in whom such levels were reached. There was one death to which procainamide may have contributed, and in this patient the plasma concentration was $10.2 \mathrm{mg}$./litre. While high doses of procainamide can depress myocardial activity, cause hypotension, and reduce atrioventricular and intraventricular conduction, these disturbances have generally occurred during rapid intravenous infusions, which must have resulted in unduly high plasma concentrations, and they were not observed. The greater stability of the plasma concentrations achieved by three-hourly oral dosage was clearly shown, double the dose at half the frequency being followed by wild fluctuations.

The Boston study has at last conclusively proved the desirability of drug prophylaxis against dysrhythmias after myocardial infarction. Procainamide is safe and effective for this purpose provided the plasma concentration can be checked. If procainamide is given to the high-risk patient with a low cardiac output or congestive heart failure the checking of plasma levels is absolutely obligatory. The drug is contraindicated if the patient has depressed atrioventricular conduction unless the ventricular rate can be guaranteed by the installation of a ventricular pacing catheter. 